Appointment of Medical Superintendent at the Ballinasloe Asylum.

The observer of contemporary life in Ireland must be struck by certain remarkable conditions. The passion of religious hatred smoulders on with an intensity inconceivable in other English-speaking countries, and although mostly hidden under the ashes of polite convention, is ever ready to burst out into consuming flame. The Local Government Act of 1898 is worked on strictly party principle, and, as the lines of political cleavage correspond pretty closely to the differences of religion, while these again are nearly coincident with social and racial distinctions, the results are curiously unlike those which the government of the people by the people has brought about in England.

The stranger to Irish methods must view with amazement the excitement which has arisen over the recent appointment of a Medical Superintendent for the Asylum for the Counties of Roscommon and Galway at Ballinasloe. It has been made the subject of protracted wrangles in the local weekly papers, has found its way into the Dublin daily press, and has even given rise to several questions in Parliament. Elsewhere we give such details of the proceedings in connection with this affair as will render it intelligible to the ordinary reader.

Any particular comment is hardly called for in these columns. Our specialty has never distinguished itself from the rest of our profession by illiberality of sentiment or a tendency to subordinate professional considerations to religious feelings. It is, of course, our opinion that appointments in any public service should be decided on service principles. Those who hold that motives of state policy dictate another course would, we think, do courageously and well to state plainly in their advertisements or prospectuses what the real conditions of employment are. At the same time we cannot think that in the future much serious injustice is to be feared, as it is perfectly understood in Ireland that the "spoils" system rules everywhere, and those who enter into public services will do so at their own peril.

\title{
Private or Pauper?
}

The note on this subject in our last issue requires correction in one or two matters of fact, which do not, however, affect 
the argument, or the conclusion reached. It is stated that the maintenance rate charged to the Guardians is 145 ., the maximum allowed by the Act. This is erroneous. The rate charged to the Guardians is I2s. Iod., and entirely covers the cost of maintenance, which is not, therefore, as stated in our article, supplemented from the county fund.

The rate charged at the Chichester Asylum for private patients is $£^{I}$ Is. per week, and the question arises whether a patient, whose friends are paying the Guardians the full maintenance rate of I2s. Iod., is entitled to be classified as a private patient. This question we held should be decided in the negative. But there is a further problem : Suppose that the friends of the patient pay such a sum, beyond the maintenance rate in the Asylum, as to recoup the Guardians for the expenses, and to remunerate them for the services, referred to in our note on the subject; ought not the patient then to be classified as a private patient ? On the reasoning applied to the matter in our note on the subject it appears that he should. But the Committee of the Asylum have fixed the rate to be paid for private patients at $£^{I}$ Is., and decline to permit a patient to be regarded as private who pays less than this sum. This seems to be rather hard measure. Neither the county nor the parish is at any expense for the patient under such circumstances, and it seems that the question should be decided on grounds of public policy. The view of the Committee may be that, in the first place, to admit private patients at a less rate than a guinea is an injustice to those that pay that sum in full ; and in the second, that it is against their own interest, and that of the ratepayers whom they represent, to accept, in any case, a lower rate, lest they may establish a precedent, and be compelled to take a lower rate in other, or perhaps in all, cases; or at any rate may foster a grievance in the minds of those for whom the full rate is paid. These are considerations which may well have weighed with the Committee, and which are entitled to respect. But there is much to be said on the other side. It is very desirable, on grounds of public policy, to avoid, where it can possibly be avoided, attaching the badge of pauperism to any man; and it is most desirable to encourage the friends of patients to make what effort they can to keep the patient above the level of pauperism. If this could be done by a payment slightly in excess of the 
maintenance rate, though not quite equal to that charged for regular patients of the private class, it seems that much good would be done, and that the evils which we have indicated would be more than counterbalanced.

The notion that a person who is made to pay a guinea for the same service and accommodation for which another pays, say, fourteen shillings, is in any way damaged, or treated with injustice, seems devoid of foundation. The practice of the medical profession is to charge fees in proportion to the means of the patient; giving the same service for the lower fee that is given for the higher; and, as the treatment of insanity is a branch of medical practice, there seems no reason why the medical rule should not apply in the case of the insane. The practice might make a difficulty in obtaining the guinea in cases in which it is now obtained without difficulty, but this slight disadvantage does not appear entitled to weigh against the manifold advantages of the course here recommended. The Committee might well follow the practice of a few of the registered hospitals, and allow on application, as an act of grace, a reduction on their full charge of a guinea, in cases in which it is shown to their satisfaction to be impracticable to obtain so much.

C. $\mathrm{M}$.

\section{Part II.-Reviews.}

Travail et Plaisir [Work and Enjoyment]. By C. Ftrt. Paris : Alcan, 1904. Pp. 476, large 8vo, 200 figures. Price I 2 frs.

This elaborate and methodical work, described by the author in the sub-title as "new experimental studies of psycho-mechanics," is certainly among Dr. Féré's most important contributions to physiological psychology, if indeed it should not be put in the first place. It has some resemblance to his early and slighter book, Sensation et Mouvement, but it embodies a far more extensive and methodical body of work. The special characteristic of Dr. Férés work generally is the unusual union of an immense literary knowledge of his subjects combined with all the practical familiarity of a laboratory student, and in the present volume this characteristic is very prominently and felicitously illustrated.

The problem which the author may here be said to have placed 